\title{
ASPEK HUMOR DALAM SYAIR SASTRA LISAN BANJAR MADIHIN
}

\author{
Endang Sulistyowati dan Ahmad Fauzan \\ Pendidikan Bahasa dan Sastra Indonesia \\ STKIP PGRI Banjarmasin \\ Jalan Sultan Adam, Komplek H. Iyus, No. 18 RT.23 Banjarmasin \\ Kalimantan Selatan. Kode pos 70121 \\ email: endangsulistyowati56@gmil.com, \\ ahmadfauzan25@rocketmail.com
}

\begin{abstract}
ABSTRAK
Penelitian ini bertujuan untuk (1) mendeskripsikan bentuk-bentuk humor yang terdapat dalam syair sastra lisan Banjar madihin dan (2) mendeskripsikan fungsi-fungsi humor yang terdapat dalam syair sastra lisan Banjar madihin.Pendekatan yang digunakan dalam penelitian ini adalah pendekatan sosiologis sastra dan jenis penelitian kepustakaan.Metode kualitatif merupakan metode yang digunakan.Sumber data yang dipakai dalam penelitian ini ialah rekaman video sastra lisan Banjar madihin.Teknik pengumpulan data menggunakan teknik dokumentasi, observasi, studi pustaka, baca, dan catat.Teknik analisis data yang digunakan adalah teknik analisis isi. Hasil penelitian menunjukkan bahwa bentuk humor yang terdapat dalam syair sastra lisan Banjar madihin meliputi: a) humor bahasa, b) humor pergunjingan, c) humor pornografi, d) humor teka-teki, e) humor kritik, dan f) humor meringankan beban pesan, sedangkan fungsi humor yang terdapat dalam syair sastra lisan Banjar madihin meliputi: a) fungsi hiburan, b) fungsi menyampaikan pesan, c) fungsi toleransi, d) fungsi memahami soal pelik, e) fungsi sindiran, dan f) fungsi kritik.
\end{abstract}

Kata kunci: aspek humor, syair, sastra lisan Banjar, madihin

\section{PENDAHULUAN}

Sastra Banjar merupakan sebutan bagi sastra yang berkembang di Kalimantan Selatan. Seperti sastra pada umumnya, sastra Banjar terbagi atas sastra lisan dan sastra tulisan. Sastra lisan hadir membudaya sejak zaman nenek moyang yang diturunkan dari mulut ke mulut di masyarakat Kalimantan Selatan dan sudah cukup banyak dari sastra lisan itu sendiri yang dibukukan untuk menjaga kelestariannya, sedangkan untuk yang berbentuk tulisan dapat dilihat dari adanya cerpencerpen dalam bahasa Banjar bahkan juga novel yang bergenre sastra Banjar.

Hari ini dengan perkembangan yang makin maju di kalangan masyarakat Kalimantan Selatan sendiri sastra Banjar masih kalah tempatnya dengan hal-hal yang berbau kemodernan. Masuknya budaya-budaya baru secara tidak langsung mengikis budaya yang sudah ada di masyarakat. Hal ini tentu mengkhawatirkan mengingat bahwa sastra Banjar adalah salah satu warisan budaya yang patut dijaga kelestariannya.Terkait kondisi tersebut kiranya sastra Banjar bisa dikatakan terancam keberadaannya, namun di tengah kondisi demikian setidaknya ada sebuah angin segar, masih dapat disaksikan beberapa pementasan sastra lisan Banjar. Salah satu eksistensinya yang cukup terjaga 
sampai saat ini adalah madihin. Madihin adalah sejenis puisi lama dalam sastra Indonesia, karena ia menyanyikan syair-syair yang berasal dari kalimat akhir yang bersamaan bunyi (Sani, 2017: 80).

Terkait madihin yang banyak pamadihin atau pamadihinan (orang yang membawakan madihin) bawakan sekarang khususnya anak muda kiblatnya lebih kepada madihin kocak yang secara bentuknya tidak terlalu mengikuti bentuk bakumadihin atau sesuai pakem, namun tentu ada juga ada yang mengikuti bentuk pakem. Madihin bentuk ini diprakarsai oleh Almarhum John Tralala yang merupakan seorang maestro madihin yang cukup ternama di kalangan masyarakat Kalimantan Selatan, bahkan nasional. Kecenderungan populernya madihin bentuk tersebut dapat dikatakan karena banyak mengandung aspek humor, sehingga menjadi sebuah hiburan tersendiri.

Pusat Bahasa (2008: 512) menyebutkan, "humor ialah sesuatu yang lucu”. Mengenai aspek humor sendiri dalam sebuah karya sastra kalau dilihat melalui sudut pandang kajian, maka ini adalah ranah sosiologi sastra. Wiyatmi (2013: 5) menyatakan sosiologi sastra merujuk pada memahami karya sastra melalui perpaduan ilmu sastra dan ilmu sosiologi (interdisipliner). Secara sederhana sosiologi sastra merupakan kajian atau pendekatan yang membahas keterkaitan antara masyarakat dan sastra. Pada kajian ini humor hadir sebagai suatu bentuk ungkapan masyarakat, sehingga ada hubungan secara langsung dengan sosiologi sastra dimana nantinya dilihat dari salah satu sastra lisan Banjar madihin.

Eksistensi madihin di kalangan masyarakat Kalimantan Selatan khususnya yang mengarah pada madihin kocak sampai sekarang menjadi menarik bagi peneliti untuk dilihat aspek humornya. Hal tersebut juga diiringi karena peneliti bergelut pada salah satu jenis sastra lisan Banjar ini yang kiblatnya juga adalah madihin kocak sebagai sarana menambah wawasan bagi peneliti terkait aspek humor dalam syair madihin. Aspek humor yang akan dilihat adalah dari segi bentuk maupun fungsinya. Penelitian ini juga diharapkan dapat memperkaya referensi perihal penelitian sastra secara umum maupun sastra Banjar, lebih jauh tentu peneliti mengharapkan penelitian ini dapat memberikan kontribusi untuk tetap menjaga eksistensi madihin utamanya di kalangan remaja, dimana perwujudan hal tersebut sumber data penelitian semuanya adalah pamadihinan muda. Remaja yang merupakan agent of change (agen dari perubahan) menjadi bagian yang cukup penting dalam pelestarian sastra lisan Banjar itu sendiri yang merupakan bagian dari sebuah budaya, sehingga salah satu sastra lisan tradisional ini tetap bergema dan lestari dari masa ke masa. 


\section{METODE}

Pendekatan yang digunakan dalam penelitian ini adalah pendekatan sosiologis. Ratna (2015: 60) menyatakan dasar filosofis pendekatan sosiologis adalah adanya hubungan hakiki antara karya sastra dengan masyarakat, dimana hubungan yang dimaksud disebabkan oleh karya sastra dihasilkan oleh pengarang, pengarang itu sendiri adalah anggota masyarakat, pengarang memanfaatkan kekayaan yang ada dalam masyarakat, dan hasil karya itu dimanfaatkan kembali oleh masyarakat. Sebagai sebuah karya sastra yang ditinjau dari segi aspek humor madihin meliputi keempat hal tersebut, walau hakikatnya jika dilihat dalam perspektif madihin tersendiri merupakan ranah antropologi sastra. Suryanata (2016: 99) mengungkapkan bahwa tujuan utama pendekatan sosiologis untuk mendapat gambaran yang lengkap dan komprehensif mengenai hubungan timbal balik antara pengarang, karya sastra, dan masyarakat. Pendekatan penelitian ini merujuk pada teori pendekatan sosiologis oleh Damono (dalam Suryanata, 2016: 100) salah satunya pendekatan yang mengutamakan teks sastra sebagai bahan kajian utama.

Metode yang digunakan dalam penelitian ini adalah kualitatif. Endraswara (2013: 51) mengungkapkan, "Metode kualitatif berkaitan dengan analisis data yang tidak mempergunakan perhitungan statistik, tetapi berupa kata-kata. Kualitas kata ditentukan oleh pengambilan data secara mendalam". Metode kualitatif adalah metode yang menyajikan bentuk deskripsi, sesuai dengan pendapat Ratna (2015: 46) bahwa metode kualitatif secara keseluruhan memanfaatkan cara-cara penafsiran dengan menyajikannya dalam bentuk deskripsi. Penggunaan metode kualitatif pada penelitian ini merujuk kepada pendeskripsian bentuk dan fungsi humor yang terdapat dalam syair sastra lisan Banjar madihin.

Adapun sumber data dalam penelitian ini merupakan rekaman-rekaman video sastra lisan Banjar madihin dengan masing-masing pamadihinanyang selanjutnya ditranskrip ke dalam bentuk teks yang meliputi:

a) Madihin Acara Banjar The Competition - Baidi (2017)

b) Madihin Acara Banjar The Competition - Ferdi Irawan dan M. Fadhil (2017)

c) Madihin Acara Banjar The Competition - M. Humaidi (2017)

d) Madihin Acara Banjar The Competition - M. Syarifuddin (2017)

e) Madihin Acara Cerdas Cermat Bahasa dan Sastra - Akmal Fitri (2017)

f) Madihin Acara Kolaborasi Hypermart-UMKM Menuju Banjarbaru Berinovasi - Gazali Rahman dan Rizki Fadilah (2018) 
g) Madihin Acara Peresmian Gedung Balai Besar Pendidikan dan Pelatihan Kesejahteraan Sosial (BBPPKS) Regional IV Kalimantan - Alba Gustia, Gazali Rahman, dan Rizki Fadilah (2017)

h) Madihin Tahun Baru 2018 - Gazali Rahman (2018)

Pada penelitian ini digunakan beberapa teknik pengumpulan data, yakni:

1) Teknik dokumentasi

2) Teknik observasi

3) Teknik studi pustaka

4) Teknik baca

5) Teknik catat

Teknik yang digunakan dalam menganalisis data adalah teknik analisis isi. Rafiek (2011) mengungkapkan, "Analisis isi adalah metode paling empiris dalam analisis tekstual, yaitu sebuah metode yang bersandar pada pengumpulan informasi numerik mengenai teks yang diteliti”. Rafiek juga menyatakan bahwasanya analisis isi merupakan bagian dari metode kuantitatif, tetapi juga dapat mendukung kajian mengenai sesuatu yang sifatnya kualitatif, sehingga sangat selaras dengan penelitian ini. Teknik analisis isi digunakan untuk menemukan bentuk dan fungsi humor dalam syair kesenian madihin.

\section{HASIL DAN PEMBAHASAN}

\section{Bentuk-bentuk Humor dalam Syair Sastra Lisan Banjar Madihin}

Setiawan (dalam Rahmanadji, 2009: 215) merujuk pada Ensiklopedia Indonesia mengungkapkan, "Humor itu kualitas untuk menghimbau rasa geli atau lucu, karena keganjilannya atau ketidakpantasannya yang menggelikan; paduan antara rasa kelucuan yang halus di dalam diri manusia dan kesadaran hidup yang iba dengan sikap simpatik".Selanjutnya Faridah (2017: 89) menyatakan bahwa humor merupakan ekspresi lucu dan mengundang tawa manusia menanggapi suatu hal tertentu baik verbal maupun nonverbal dengan respon terhadap sesuatu yang lucu. Dapat diambil garis besar bahwa pengertian humor adalah sesuatu yang lucu yang dapat mengundang tawa, tidak hanya mengundang tawa humor juga dapat menimbulkan kegelian.

Humor yang diketahui merupakan sesuatu yang lucu kiranya memiliki berbagai macam bentuk. Jarkasi (2002: 48-54) senada dengan Huda (2015: 48-50) memaparkan bentuk humor, yakni sebagai berikut:
a) Humor bahasa
b) Humor tingkah laku
c) Humor pergunjingan 
d) Humor pornografi

Sedikit berbeda Rahmanadji (2009: 218) membagi humor dalam kriterium tertentu yang meliputi:

1) Kriterium indrawi: humor verbal, humor visual, dan humor auditif

2) Kriterium bahan: humor politis, humor seks, humor sadis, dan humor teka-teki

3) Kriterium etis: humor sehat (humor yang edukatif) dan humor yang tidak sehat

4) Kriterium estetis: humor tinggi dan humor rendah

Berdasarkan golongannya Pramono (dalam Rahmanadji, 2009: 218) membagi humor berdasarkan dua golongan, yakni: “(1) humor menurut penampilannya, yang terdiri atas: humor lisan, humor tulisan atau gambar, dan humor gerakan tubuh; (2) menurut tujuan dibuatnya atau tujuan pesannya, humor terdiri atas: humor kritik, humor meringankan beban pesan, dan humor semata-mata pesan".

Sebagai pembatas masalah dalam penelitian ini, adapun indikator bentuk humor dalam penelitian ini merujuk pada bentuk-bentuk humor di atas, yakni:

a) Humor bahasa

b) Humor pergunjingan

c) Humor pornografi

d) Humor teka-teki

e) Humor kritik

f) Humor meringankan beban pesan

Bentuk-bentuk humor dalam syair sastra lisan Banjar madihin secara lebih jelas dipaparkan satu per satu sebagai berikut.

\section{a. Humor Bahasa dalam Syair Sastra Lisan Banjar Madihin}

"Humor bahasa adalah kelucuan-kelucuan yang disebabkan oleh penuturan kalimat atau ungkapan-ungkapan bahasa" (Jarkasi, 2002: 49). Berangkat dari pengertian tersebut dapat dipahami bahwa humor bahasa merupakan humor yang menggunakan ungkapan bahasa dalam penyampaiannya. Humor bahasa pun dapat ditemui pada syair-syair sastra lisan Banjar madihin.Madihin yang merupakan bentuk sebuah sastra lisan tidak akan terlepas dari sebuah bahasa, sebab bahasa sendiri merupakan media dari sastra tersebut, sekaligus menegaskan bahwa humor bahasa sangat memungkinkan terdapat dalam syair madihin. Berikut penggalan-penggalan syair madihin yang memuat bentuk humor bahasa. 
Dihadiri sangat banyak panonton yang setia meliat (Dihadiri sangat banyak penonton yang setia melihat)

Di muka ulun para juri terhormat (Di depan saya para juri terhormat)

Juga para penonton makin datang babanyak (Juga para penonton datang semakin banyak)

Ada nang datang inya lawan pacar masra pina baragap (Ada yang datang dia bersama pacar mesra seperti berpelukan)

Ada nang jomblo duduk saurangan muha pina pucat (Ada yang tidak punya pasangan atau pacar duduk sendiri wajah seperti pucat)

Mungkin saja pacarnya selingkuh itu diambil sahabat (Mungkin saja pacarnya selingkuh itu diambil sahabat)

Atau jua dompetnya karing itu lagi sekarat (Atau juga dompetnya kering itu lagi sekarat)

Agar suasana malam ini tambah semangat (Agar suasana malam ini tambah semangat)

Dan seterusnya....

(Madihin Acara Banjar The Competition - Baidi, 2017)

Lalu di sini ulun handak mandoa akan (Lalu di sini saya mau mendoakan)

Mudah-mudahan nang hadir di sini rahmat dicurahkan (Semoga yang hadir di sini rahmat dicurahkan)

Nang bapasangan mudahan diawet akan (Yang berpasangan semoga diawetkan)

Kalau nang jomblo mudahan dapat pasangan (Kalau yang jomblo semoga dapat pasangan)

Nang ma aamiin akan mudahan dikabul akan (Yang meng aamiin kan semoga dikabulkan)

Nang kada ma aamiin akan bilanya mati masuk ka dalam kuburan (Yang tidak meng aamiin kan kalaunya meninggal masuk ke dalam kuburan)

Dan seterusnya....

(Madihin Acara Banjar The Competition - M. Humaidi, 2017)

Pada madihin acara Banjar The Competition yang dibawakan Baidi humor bahasa terdapat dalam larik "Ada nang jomblo duduk saurangan muha pina pucat" yang artinya "Ada yang tidak punya pasangan atau pacar duduk sendiri wajah seperti pucat”. Larik tersebut pamadihin sampaikan secara umum menggunakan bahasa Banjar sebagai jalan menyampaikan perihal humor dengan menyatakan bahwa ada yang tidak punya pasangan atau jomblo duduk sendiri dan wajah seperti pucat. Bahasa memegang peranan penting dalam tersampaikannya humor, sehingga jelas bahwa larik tersebut merupakan suatu bentuk humor bahasa.

Madihin acara Banjar The Competition oleh M. Humaidi memuat sebuah bentuk humor bahasa yakni pada larik-larik "Nang ma aamiin akan mudahan dikabul akan" dan "Nang kada ma aamiin akan bilanya mati masuk ka dalam kuburan" yang memiliki arti "Yang meng aamiin kan semoga dikabulkan" dan "Yang tidak meng aamiinkan kalaunya meninggal masuk ke dalam kuburan". Humor yang disampaikan pada larik-larik tersebut ialah perihal yang tidak meng aamiinkan kalaunya meninggal masuk ke dalam kuburan. Bentuk humor dapat dilihat bahwa sebenarnya orang yang meng aamiinkan pun kalaunya meninggal tetap akan ke dalam kuburan (dalam perspektif agama Islam). Pada madihin digunakan umumnya bahasa Banjar sebagai media 
menyampaikan humor tersebut dan dapat dinyatakan bahwa larik-larik yang dimaksud merupakan bentuk humor bahasa.

\section{b. Humor Pergunjingan dalam Syair Sastra Lisan Banjar Madihin}

Humor pergunjingan merupakan bentuk humor yang disampaikan melalui ejekan. Jarkasi (2002: 52) menyatakan bahwa humor pergunjingan dapat dipahami adalah humor yang digunakan untuk saling mengejek. Berangkat dari hal tersebut, maka humor pergunjingan dapat pula dikatakan sebuah bentuk humor ejekan. Pada sastra lisan Banjar madihin bentuk humor pergunjingan atau ejekan dapat dilihat dalam penggalan syair berikut ini.

Sebalum berlajut kita perkenalan dulu lawan buhan pian ulun handak bapadah nama (Sebelum berlanjut kita perkenalan dulu dengan kalian saya mau memberi tahu nama) (Fadhil)

Perkenalkan Muhammad Fadhil itu nama saya ig ulun fadhilghalianan silakan difollow saja(Perkenalkan Muhammad Fadhil itu nama saya ig sayafadhilghalianan silakan difollow saja) (Fadhil)

Kada jauh beda lawan Afgan tentunya (Tidak jauh beda dengan Afgan tentunya)(Fadhil)

Bujur dari jauh ulun mirip Sandiaga Uno calon gubernur Jakarta(Benar dari jauh mirip Sandiaga Uno calon gubernur Jakarta) (Fadhil)

Bujur dari jauh mirip Sandiaga Uno itu bakacamata (Benar dari jauh mirip Sandiaga Uno itu berkacamata) (Ferdi)

Sekali diparaki mirip tukang batu akik ini di Martapura (Waktu didekati mirip tukang batu akik di Martapura) (Ferdi)

(Madihin Acara Banjar The Competition - Ferdi Irawan dan M. Fadhil, 2017)

Penggalan syair di atas dibawakan oleh pamadihinan secara berpasangan yaitu Ferdi Irawan dan M. Fadhil. Penggalan syair yang bergaris bawah dibawakan oleh Ferdi dan ditujukan kepada Fadhil. Pada syair yang dimaksud Ferdi menyatakan bahwa benar Fadhil mirip Sandiaga Uno, tetapi kalau dekat mirip tukang batu akik. Jelas bahwa larik tersebut merupakan sebuah bentuk ejekan yang mana objeknya adalah Fadhil, bersamaan dengan itu larik yang demikian apabila dituturkan tentu akan mengundang tawa penonton, sehingga dapat dikatakan larik yang dibawakan oleh Ferdi merupakan bentuk humor pergunjingan atau ejekan.

\section{c. Humor Pornografi dalam Syair Sastra Lisan Banjar Madihin}

Perihal humor pornografi Jarkasi (2002: 54) mengungkapkan, "Humor pornografi adalah kelucuan-kelucuan yang ditimbulkan oleh pikiran asosiatif terhadap hal-hal yang berbau sex". Humor pornografi atau seks juga termasuk dalam kriterium tertentu pada humor yakni humor kriterium bahan (Rahmanadji, 2009: 218). Merujuk pada hal-hal tersebut dapat dikatakan bahwa humor pornografi sebagai humor yang mengundang pikiran-pikiran yang mengarah pada sesuatu yang berbau seks. Terkait syair madihin yang memiliki humor pornografi yakni sebagai berikut. 
Amun bini ikam samisal menstruasi (Kalau istri kamu semisal menstruasi) (Rizki)

Tulak ka Hypermart tukar pambalut nang lumbah(Pergi ke Hypermart beli pembalut yang besar)(Gazali)

Amun bini ikam batagih tv hanyar(Kalau istri kamu meminta tv baru)(Rizki)

Tulak ka Hypermart tukarakan tv ganal itu nang kaya rumah(Pergi ke Hypermart belikan tv besar itu yang seperti rumah)(Gazali)

Amun bini ikam kaina handak baranak(Kalau istri kamu nanti mau melahirkan)(Rizki)

Tulak ka Hypermart perlengkapan bayi terjangkau jua murah(Pergi ke Hypermart perlengkapan bayi terjangkau juga murah)(Gazali)

Amun bini ikam ini mambari kode itu pas malam sunah (Kalau istri kamu ini memberi kode itu waktu malam sunah) (Rizki)

Jangan tulak ka Hypermart gawi haja di rumah(Jangan pergi ke Hypermart kerjakan saja di $\underline{\text { rumah)(Gazali) }}$

(Madihin Acara Kolaborasi Hypermart-UMKM - Gazali Rahman dan Rizki Fadilah, 2018)

Pada penggalan syair madihin yang dibawakan oleh Gazali Rahman dan Rizki Fadilah humor pornografi mengungkapkan perihal orang yang memiliki istri dan kalau istri memberi kode di malam sunah, kerjakan saja di rumah jangan di Hypermart. Penggalan syair tersebut kiranya dapat mengundang pikiran-pikiran yang berbau pornografi atau seks bagi penonton yang mendengarkan perihal suatu malam yang berkenaan dengan suami istri dan dikatakan mengerjakan atau melakukannya di rumah saja. Larik-larik yang pamadihinan sampaikan juga tentu sarat akan nilai humor mengingat disampaikan secara samar perihal yang berbau seks tersebut sehingga ada indikasi mengundang tawa pendengar atau penonton. Jadi, larik-larik yang dimaksud merupakan suatu bentuk humor pornografi atau seks yang diujarkan oleh pamadihinan.

\section{d. Humor Teka-teki dalam Syair Sastra Lisan Banjar Madihin}

Humor teka-teki dapat dipahami sebagai humor yang dapat menimbulkan sebuah pertanyaan atau teka-teki. Sebagai gambaran humor teka-teki yang terdapat dalam syair madihin, berikut contoh penggalan syair yang dibawakan oleh M. Syarifuddin dalam Acara Banjar The Competition.

Mambaca buku pengetahuan tak sempit (Membaca buku pengetahuan tidak sempit)

Mambaca tulisan abcd sampai $z$ (Membaca tulisan abcd sampai z)

Mambaca Al-Qur'an dilancari batajwid (Membaca Al-Qur'an dilancarkan bertajwid)

Mambaca buku nikah jujurannya sakit (Membaca buku nikah jujurannya susah)

Mambaca binian itu pang lah sulit (Membaca perempuan itu jelaslah sulit)

Mambaca kode itu sangat rumit (Membaca kode itu sangat rumit)

Tapi satu hal mambaca paling asik (Tetapi satu hal membaca paling asik)

Mambaca buku amal karangan Raqib 'Atid (Membaca buku amal karangan Raqib 'Atid)

(Madihin Acara Banjar The Competition - M. Syarifuddin, 2017)

Pada larik-larik tersebut pamadihinan menyampaikan perihal macam-macam membaca, diungkapkan oleh pamadihinan bahwa membaca buku nikah jujurannyasusah, membaca 
perempuan itu sulit, dan membaca kode itu rumit. Paparan macam-macam membaca oleh pamadihinan tersebut juga selanjutnya diungkapkan ada satu hal membaca paling asik, bagian tersebut kiranya memunculkan pertanyaan mengenai membaca seperti apa yang dimaksud dan menegaskan larik tersebut merupakan bentuk teka-teki. Pada bagian-bagian larik tersebut juga sarat akan nilai humor apabila dituturkan, tepatnya pada larik yang menyatakan bahwa membaca yang paling asik seperti diujarkan sebelumnya ternyata adalah membaca buku amal karangan Raqib 'Atid. Berangkat dari hal-hal tersebut jelaslah bahwa larik-larik yang dimaksud merupakan suatu bentuk humor teka-teki.

\section{e. Humor Kritik dalam Syair Sastra Lisan Banjar Madihin}

Pamadihinan pada saat membawakan madihin kadang pula menuturkan humor yang sifatnya mengkritik. Sebagai gambaran yang lebih jelas berikut contoh penggalan syair madihin yang membubuhkan humor kritik.

Ujar babinian ulun mirip artis urang Malaysia itu bangaran Thomas (Kata wanita saya mirip artis orang Malaysia itu namanya Thomas)

Bagi babinian mun handak kenal ulun itu lebih jelas (Bagi wanita kalau mau kenal saya itu lebih jelas)

Bisa daftarkan diri capati lakas-lakas (Bisa daftarkan diri segera cepat-cepat)

Kaina ulun bawa ke kantor KUA tunangan bahuruf utas (Nanti saya bawa ke kantor KUA tunangan bertukar cincin)

Asalkan jujuran kada labih lima blas (Asalkan jujuran tidak lebih lima belas)

(Madihin Acara Banjar The Competition - Baidi, 2017)

Jujuran yang dimaksud dalam teks adalah salah satu budaya Banjar terkait pernikahan berkenaan dengan uang yang wajib diberikan kepada calon pengantin perempuan oleh calon pengantin laki-laki. Larik tersebut kalau dilihat secara mendalam mempunyai makna mengkritik perihal jujuran yang cukup tinggi yakni di atas lima belas juta rupiah, sebab hal tersebut pamadihinan katakan bahwasanya dia meminta agar tidak lebih dari lima belas juta tersebut. Walaupun larik tersebut memiliki makna mengkritik dapat disadari juga larik tersebut memiliki nilai kelucuan tersendiri, sehingga pada bagian larik ini dapat dikategorikan sebagai bentuk humor kritik.

\section{f. Humor Meringankan Beban Pesan dalam Syair Sastra Lisan Banjar Madihin}

Humor merupakan sesuatu yang lucu secara tidak langsung dapat meringankan beban pesan yang akan disampaikan, sebab walau pesan yang disampaikan perihal berat dengan humor yang 
membuat orang tertawa maka hal tersebut tidak terlalu dirasakan. Humor meringankan beban pesan dapat ditemui dalam penggalan syair sastra lisan Banjar Madihin di bawah ini.

Mirip Rano Karno padahal punya muka mirip Pokemon Pikachu (Mirip Rano Karno padahal wajah mirip Pokemon Pikachu) (Gazali)

Adapun kami di sini handak mengaku (Adapun kami di sini mau mengaku) (Gazali)

Mumpung banyak inilah bapak ibu (Mumpung banyak inilah bapak ibu) (Gazali)

Tujuan madihin ini kami hanya satu (Tujuan madihin ini kami hanya satu) (Gazali)

Kalau ada yang mengenal kami jadi menantu (Kalau ada yang mengenal kami jadi menantu) (Gazali)

(Madihin Acara Peresmian Gedung Balai Besar Pendidikan dan Pelatihan Kesejahteraan Sosial (BBPPKS) Regional IV Kalimantan - Alba Gustia, Gazali Rahman, dan Rizki Fadilah, 2017)

Penggalan syair yang dibawakan oleh Gazali Rahman tersebut mengungkapkan perihal tujuan madihin Gazali dan teman-temannya yakni hanya satu bahwa kalau-kalau mereka dijadikan menantu oleh bapak atau ibu yang hadir pada gelaran acara. Bagian-bagian tersebut apabila diujarkan tentu akan mengundang tawa penonton sebagai suatu bentuk humor. Pesan yang disampaikan oleh Gazali pada penggalan syair disadari bernilai berat yakni perihal jadi menantu, namun bagian tersebut dikemas dengan humor sehingga pesan yang disampaikan terasa ringan saat didengar. Berdasarkan hal-hal tersebut, jelas bahwa penggalan syair yang dibawakan oleh Gazali tersebut masuk pada kategori humor meringankan beban pesan.

\section{Fungsi-fungsi Humor dalam Syair Sastra Lisan Banjar Madihin}

Sebagai sesuatu yang lucu kiranya humor memiliki beragam fungsi. Humor hadir bukan sertamerta hanya untuk membuat orang-orang yang menikmatinya tertawa, tetapi lebih jauh ada banyak fungsi dari humor tersebut. Sujoko (dalam Rahmanadji, 2009: 218) menyatakan tujuh fungsi humor, “(1) melaksanakan segala keinginan dan segala tujuan gagasan atau pesan; (2) menyadarkan orang lain bahwa dirinya tidak selalu benar; (3) mengajar orang melihat persoalan dari berbagai sudut; (4) menghibur; (5) melancarkan pikiran; (6) membuat orang mentoleransi sesuatu; (7) membuat orang memahami soal pelik".

Kalau melihat di era sekarang humor kadang orang-orang gunakan sebagai sarana sindiran atau kritikan sebut saja kepada pemerintah. Hal tersebut menegaskan bahwasanya fungsi humor juga sebagai sarana mengkritik. Sejalan dengan ini Sujoko (dalam Rahmanadji, 2009: 220) mengemukakan bahwa "Di Indonesia kalangan mahasiswa gemar menggunakan humor sebagai sarana kritik sosial". Tidak sebatas hanya sebagai sarana kritik sosial, Setiawan (dalam Rahmanadji, 2009: 220) mengatakan, "Humor juga berfungsi sebagai rekreasi. Maksud rekreasi di sini humor digunakan untuk menghilangkan kejenuhan". 
Berdasarkan beberapa fungsi humor yang telah dipaparkan maka dapat diambil dan disimpulkan fungsinya secara umum, yakni:

a) Menyampaikan pesan

b) Membuat orang mentoleransi

c) Membuat orang memahami soal pelik

d) Menghibur

e) Melancarkan pikiran

f) Sarana sindiran

g) Sarana mengkritik

Sebagai pembatas masalah dalam penelitian ini, adapun indikator fungsi humor dalam penelitian ini merujuk pada fungsi-fungsi humor tersebut, yakni:

a) Fungsi hiburan

b) Fungsi menyampaikan pesan

c) Fungsi toleransi

d) Fungsi memahami soal pelik

e) Fungsi sindiran

f) Fungsi kritik

Fungsi-fungsi humor dalam syair sastra lisan Banjar madihin secara lebih jelas dipaparkan satu per satu sebagai berikut.

\section{a. Fungsi Hiburan dalam Syair Sastra Lisan Banjar Madihin}

Secara umum walaupun tanpa aspek humor, madihin sejatinya sudah memiliki fungsi sebagai sebuah hiburan. Berikut penggalan syair madihin yang humornya memiliki fungsi hiburan.

Nang di muka ulun ada buhan Duta TV mangamera di situ (Yang di depan saya ada mereka dari Duta TV merekam di situ)

Nang subalah kanan ada pembawa acara aduhai sidin bapupur ini habang gincu(Yang sebelah kanan ada pembawa acara aduhai beliau berpupur ini merah gincu)

Nang subalah kiri banyak peserta inya duduk di bangku(Yang sebelah kiri banyak peserta dia duduk di kursi)

Agar suasana hari ini tambah seru(Agar suasana hari ini tambah seru)

Mari semuanya bertepuk tangan dulu(Mari semuanya bertepuk tangan dulu)

(Madihin Acara Cerdas Cermat Bahasa dan Sastra - Akmal Fitri, 2017)

Pada larik tersebut pamadihinan menyampaikan bahwa orang yang di sebelah kanan yakni pembawa acara menggunakan pupur dan gincu merah. Bagian larik yang demikian tentu mempunyai indikasi mengundang tawa penonton yang menyaksikan apabila dituturkan oleh Akmal 
Fitri sebagai pamadihinan dan dapat dikatakan larik tersebut merupakan suatu bentuk humor. Dituturkannya bentuk humor yang merupakan perihal lucu kiranya menjadi hiburan tersendiri bagi penonton, selain madihin yang secara utuh juga berfungsi sebagai hiburan apabila dipentaskan. Berangkat dari hal-hal tersebut maka jelas bahwa larik yang dimaksud masuk pada kategori humor yang dapat berfungsi sebagai hiburan.

\section{b. Fungsi Menyampaikan Pesan dalam Syair Sastra Lisan Banjar Madihin}

Walaupun humor berkenaan dengan hal jenaka, namun tidak semata-mata untuk ditertawakan saja, kadang humor tersebut memiliki fungsi menyampaikan suatu pesan. Adapun syair sastra lisan Banjar yang mengandung fungsi humor menyampaikan pesan yakni sebagai berikut.

Dua ribu lapan belas sadang barancana kamu (Dua ribu delapan belas pas berencana kamu) Sadang sudah mahanyari kalambu (Pas sudah membarui kelambu)

Sadang sudah baurusan ka panghulu (Pas sudah berurusan ke penghulu)

Sadang mancari calon ka hilir ka hulu (Pas mencari calon ke hilir ke hulu)

Amunnya mambujang talalu lawas ini bisa barisiku (Kalaunya membujang terlalu lama ini bisa beresiko)

Kalu pina kacanduan saban malam tapalar sabun rinso (Kalau-kalau kecanduan setiap $\underline{\text { malam menggunakan sabun rinso) }}$

(Madihin Tahun Baru 2018 - Gazali Rahman, 2018)

Pesan yang disampaikan pamadihinan dalam penggalan tersebut adalah perihal kalau terlalu lama membujang. Selain pesan yang dimaksud pamadihinan juga menyampaikan kalau-kalau kecanduan setiap malam menggunakan sabun rinso yang memiliki makna dalam tanda kutip kegiatan negatif. Larik-larik tersebut kiranya menjadi kelucuan atau humor tersendiri bagi penonton pada saat dituturkan, sehingga dapat dikatakan penggalan syair yang dimaksud masuk pada kategori sebuah humor yang berfungsi menyampaikan suatu pesan.

\section{c. Fungsi Toleransi dalam Syair Sastra Lisan Banjar Madihin}

Humor yang berfungsi sebagai toleransi lebih kepada humor yang membuat orang menoleransi sesuatu. Toleransi sendiri di antaranya memiliki arti menghargai. Contoh penggalan syair madihin yang memuat fungsi humor toleransi.

Lalu juga banyak ibu-ibu bapak-bapak (Lalu juga banyak ibu-ibu bapak-bapak)

Pakai sasirangan warnanya nyarak-nyarak (Menggunakan sasirangan warnanya terangterang)

Ada baju ungu habang jua coklat (Ada baju ungu merah juga cokelat)

Ada nang bakacamata hidung sidin sadikit mitak (Ada yang berkacamata hidung beliau sedikit pesek)

Lawan ada jua nang di balakang kepala sidin botak (Dan ada juga yang di belakang kepala $\underline{\text { sidin botak) }}$ 
Dan seterusnya....

(Madihin Acara Kolaborasi Hypermart-UMKM - Gazali Rahman dan Rizki Fadilah, 2018)

Penggalan syair madihin tersebut mengungkapkan perihal tertentu kepada penonton bahwasanya ada penonton yang memakai kacamata berhidung pesek dan ada juga penonton di belakang yang berkepala botak. Larik-larik tersebut boleh saja mempunyai nilai ejekan di dalamnya, namun di sisi lain merupakan bentuk penghormatan atau penghargaan kepada penonton yang hadir. Ejekan yang hadir di dalam penggalan syair tersebut pun tentunya untuk melahirkan tawa penonton yang hadir sebagai sebuah bentuk humor. Ejekan pada penggalan syair kiranya ditujukan kepada orang yang lebih tua, karena pamadihinan menggunakan kata sapaan 'sidin' yang padanannya kurang lebih adalah 'beliau'. Kalau disampaikan secara langsung tentu hal tersebut tidak etis, tetapi dalam konteks ini disampaikan dalam sebuah madihin dan kemasan humor sehingga hal tersebut dapat ditoleransi oleh orang yang mendengar. Berdasarkan hal-hal tersebut, maka jelas bahwa larik-larik yang dimaksud merupakan sebuah humor yang mempunyai fungsi toleransi.

\section{d. Fungsi Memahami Soal Pelik dalam Syair Sastra Lisan Banjar Madihin}

Salah satu fungsi dari humor adalah memahami soal pelik. Humor yang dimaksud salah satunya tergambar dalam penggalan syair madihin di bawah ini.

Ulun di sini ulun pang jujur ini wani suwer(Saya di sini saya jujur ini berani suwer) Nang ngaran mambaca ulun ini pangoler(Yang namanya membaca saya ini pemalas) Akibatnya otak buntu bajalan kiwir-kiwir(Akibatnya otak tidak cerdas berjalan tidak karuan) Tapi tak mengapa itu pang ternyata banyak yang pangoler(Tetapi tidak mengapa itu ternyata banyak yang pemalas)

Minat baca orang Indonesia peringkat yang terakhir(Minat baca orang Indonesia peringkat yang terakhir)

Inilah tentu sebuah pengamatan yang membuat gigir(Inilah tentu sebuah pengamatan yang membuat geger)

Haraga buku nang bagus-bagus itu mahal-mahal tiada yang mentraktir (Harga buku yang bagus-bagus itu mahal-mahal tiada yang mentraktir)

Dan seterusnya....

(Madihin Acara Banjar The Competition - M. Syarifuddin, 2017)

Persoalan pelik yang disampaikan pamadihinan pada larik-larik tersebut adalah perihal minat baca orang Indonesia ternyata peringkat terakhir dan merupakan sebuah pengamatan yang membuat geger. Diujarkannya bagian tersebut oleh pamadihinan kiranya ingin menyampaikan bahwa minat baca orang Indonesia mengkhawatirkan. Hal tersebut tentu bukan perihal sederhana dan cukup pelik, namun dalam hal ini pamadihinan mengemas syair dengan menambahkan nilai-nilai humor sebelum mengujarkan permasalahan pelik tersebut, misalnya dengan mengatakan dia pemalas 
dalam hal membaca yang membuat otaknya tidak cerdas bahkan mengatakan banyak juga yang pemalas. Pengemasan persoalan pelik dengan humor dalam larik-larik tersebut menegaskan bahwa bagian-bagian tersebut merupakan syair yang memuat humor dan berfungsi sebagai jalan memahami persoalan yang pelik.

\section{e. Fungsi Sindiran dalam Syair Sastra Lisan Banjar Madihin}

Humor yang dapat mengundang tawa salah satunya bisa berfungsi sebagai sarana sindiran. Berikut syair madihin yang memuat fungsi humor sebagai sindiran.

Juga dewan juri yang saya hormati ini duduk berdua (Juga dewan juri yang saya hormati ini duduk berdua)

Kalau tidak salah tadi ada batiga (Kalau tidak salah tadi ada bertiga)

Juri yang satunya ini pang ka mana (Juri yang satunya ini ke mana)

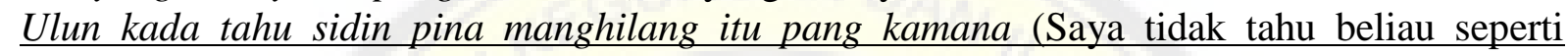
menghilang ini ke mana)

Supaya lebih meriah tepuk tangan semuanya (Supaya meriah tepuk tangan semuanya)

(Madihin Acara Banjar The Competition - M. Syarifuddin, 2017)

Larik-larik yang disampaikan oleh pamadihinan tersebut memiliki nilai sindiran halus yang ditujukan kepada dewan juri, pamadihinan mengungkapkan penghormatan kepada dewan juri yang duduk berdua seraya menambahkan kalau tidak salah juri tadinya ada bertiga, dan satu juri tidak tahu pergi ke mana. Pada hal tersebut yang menjadi objek sindiran pamadihinan adalah satu juri yang menghilang. Walaupun berupa sebuah sindiran namun ujaran-ujaran pamadihinan tersebut kiranya dapat mengundang tawa pendengar. Jadi, larik-larik tersebut merupakan sebuah humor yang difungsikan sebagai sebuah sindiran.

\section{f. Fungsi Kritik dalam Syair Sastra Lisan Banjar Madihin}

Jika bentuk humor terdapat bentuk humor kritik, yang mana isi dari humor berkenaan dengan suatu kritik yang disampaikan oleh pamadihinan. Contoh penggalan syair madihin yang memuat fungsi humor kritik.

Ujar babinian ulun mirip artis urang Malaysia itu bangaran Thomas (Kata wanita saya mirip artis orang Malaysia itu namanya Thomas)

Bagi babinian mun handak kenal ulun itu lebih jelas (Bagi wanita kalau mau kenal saya itu lebih jelas)

Bisa daftarkan diri capati lakas-lakas (Bisa daftarkan diri segera cepat-cepat)

Kaina ulun bawa ke kantor KUA tunangan bahuruf utas (Nanti saya bawa ke kantor KUA tunangan bertukar cincin)

Asalkan jujuran kada labih lima blas (Asalkan jujuran tidak lebih lima belas)

(Madihin Acara Banjar The Competition - Baidi, 2017) 
Seperti halnya bentuk humor kritik, pada madihin yang dibawakan oleh Baidi fungsi kritik tentu juga terdapat pada bagian larik "Asalkan jujurankada labih lima belas" yang artinya "Asalkan jujuran tidak lebih lima belas". Pada hal ini selain sebagai bentuk humor larik tersebut pamadihinan fungsikan untuk memberikan kritik perihal jujuran agar nilainya tidak terlalu tinggi yakni di atas lima belas juta rupiah dan yang diinginkan dalam larik tersebut adalah cukup lima belas juta rupiah atau lebih rendah.

\section{SIMPULAN}

Berangkat dari tujuan penelitian dan hasil analisis mengenai aspek humor dalam syair sastra lisan Banjar madihin, maka peneliti dapat menarik kesimpulan sebagai berikut:

(1) Berdasarkan sumber data yang ada secara keseluruhan bentuk-bentuk humor dalam syair sastra lisan Banjar madihin meliputi: (a) humor bahasa, (b) humor pergunjingan atau ejekan, (c) humor pornografi atau seks, (d) humor teka-teki, (e) humor kritik, dan (f) humor meringankan beban pesan.

(2) Berdasarkan sumber data yang ada secara keseluruhanfungsi-fungsi humor dalam syair sastra lisan Banjar madihin meliputi: (a) fungsi hiburan, (b) fungsi menyampaikan pesan, (c) fungsi toleransi, (d) fungsi memahami soal pelik, (e) fungsi sindiran, dan (f) fungsi kritik.

\section{SARAN}

Berdasarkan uraian hasil analisis dan simpulan yang telah peneliti paparkan terkait aspek humor yang terdapat dalam syair sastra lisan Banjar madihin, peneliti memberikan saran-saran sebagai berikut.

1) Bagi pembaca, peneliti mengharapkan supaya tidak hanya mengetahui madihin sebatas sebuah sastra lisan Banjar atau kesenian Banjar, namun juga nilai-nilai yang terkandung di dalamnya.

2) Bagi peneliti sastra selanjutnya, diharapkan dapat menggali lebih dalam dan lebih luas sastra lisan Banjar madihin dengan kajian dan perspektif sastra yang beragam.

3) Bagi penikmat sastra atau masyarakat, tidak hanya sekadar menikmati, namun peneliti juga mengharapkan dapat mengapresiasi dan memberikan dukungan terhadap karya sastra dalam bentuk apapun. 


\section{DAFTAR RUJUKAN}

Endraswara, Suwardi. 2013. Metodologi Penelitian Antropologi Sastra. Yogyakarta: Penerbit Ombak.

Faridah, Siti. 2017. Teknik Penciptaan Humor dalam Madihin Banjar. Makalah disajikan dalam rangka Seminar Nasional Pembelajaran Bahasa dan Sastra Indonesia Berbaris Kearifan Lokal dalam Pembentukan Karakter Bangsa, PBSI FKIP Universitas Muria Kudus, Kudus, 18 Mei 2017.

Huda, Sirajul. 2015. Struktur, Karakter Tokoh, dan Bahasa dalam Kesenian Tradisional Mamanda. Banjarmasin: Pusaka Banua.

Jarkasi. 2002. Mamanda Seni Pertunjukan Banjar dari Realitas Tradisional ke Kesenian Populer. Banjarmasin: PT Grafika Wangi Banjarmasin.

Khatibah. 2011. Penelitian Kepustakaan. Jurnal Iqra', 05(1): 36.

Pusat Bahasa. 2008. Kamus Besar Bahasa Indonesia. Cetakan Pertama Edisi IV. Jakarta: PT Gramedia Pusaka Utama.

Rafiek, M.. 2011. Metode dan Teknik Penelitian Sastra. Makalah disajikan dalam rangka kegiatan Penerapan Teknik dan Metode Penelitan, Balai Bahasa Provinsi Kalimantan Tengah, Palangka Raya, 6-8 November 2011.

Rahmanadji, Didiek. 2009. Sejarah, Teori, Jenis, dan Fungsi Humor. Jurnal Ilmiah Fakultas Sastra Universitas Negeri Malang, 213.

Ratna, Nyoman Kutha. 2015. Teori, Metode, dan Teknik Penelitian Sastra. Cetakan Kedelapan. Yogyakarta: Pustaka Pelajar.

Sani, M. Budi Zakia. 2017. Kesenian Madihin di Banjarmasin Kalimantan Selatan dalam Tinjauan Aksiologi dan Relevansinya Terhadap Pendidikan Karakter. Jurnal Imaji, 15(1): 80.

Suryanata, Jamal T.. 2016. Pengkajian Drama. Daerah Istimewa Yogyakarta: AKAR Indonesia.

Tim Penyusun. 2016. Pedoman Penulisan Skripsi. Cetakan Kesepuluh. Banjarmasin: STKIP PGRI Banjarmasin.

Wiyatmi. 2013. Sosiologi Sastra. Yogyakarta: Kanwa Publisher. 